\title{
Human papillomavirus predicts the outcome following concomitant chemoradiotherapy in patients with head and neck squamous cell carcinomas
}

\author{
ANAËLLE DURAY ${ }^{1 *}$, GÉRALDINE DESCAMPS $^{1 *}$, CHRISTINE DECAESTECKER ${ }^{2}$, \\ NICOLAS SIRTAINE ${ }^{3}$, ANDRÉ GILLES ${ }^{5}$, MOHAMAD KHALIFÉ ${ }^{5}$, GILBERT CHANTRAIN $^{4}$, \\ CHRISTOPHE E. DEPUYDT ${ }^{6}$, PHILIPPE DELVENNE ${ }^{7}$ and SVEN SAUSSEZ $^{1,4}$
}

\begin{abstract}
${ }^{1}$ Laboratory of Anatomy, Faculty of Medicine and Pharmacy, University of Mons, Mons; ${ }^{2}$ Laboratory of Toxicology, Institute of Pharmacy, ${ }^{3}$ Department of Pathology, Faculty of Medicine, Institut Bordet, ${ }^{4}$ Department of Oto-Rhino-Laryngology, CHU Saint-Pierre, Free University of Brussels, Brussels; ${ }^{5}$ Department of Pathology, RHMS Baudour, Mons; ${ }^{6}$ Laboratory for Clinical Pathology and Molecular Biology (LaboLokeren, Campus Riatol), Antwerp; ${ }^{7}$ Department of Pathology, CHU Sart-Tilman, University of Liège, Liège, Belgium
\end{abstract}

Received November 30, 2012; Accepted December 27, 2012

DOI: $10.3892 / o r .2013 .2415$

\begin{abstract}
We investigated the prevalence of human papillomavirus (HPV) in a clinical series of 72 patients with head and neck squamous cell carcinoma (HNSCC) using a retrospective and prospective study design. The majority of patients were smokers and/or drinkers and were treated with concomitant chemoradiotherapy (CCR). Furthermore, we assessed the impact of HPV positivity on the response to CCR. Paraffin-embedded samples from HNSCC patients $(n=72)$ were evaluated for the presence of HPV DNA using both $\mathrm{GP}^{+} / \mathrm{GP}^{+}$consensus PCR and type-specific E6/E7 PCR to detect HPV types $6,11,16,18,31,33,35,39,45$, $51,52,53,56,58,59,66,67$ and 68 . The type-specific E6/ E7 PCR demonstrated that 20 out of 69 HNSCC patients (29\%) presented with high-risk (HR) HPV types and that 5 of the 69 HNSCC patients (7\%) presented with low-risk (LR) $\mathrm{HPV}$ types. Using the $\mathrm{GP}^{+} / \mathrm{GP}^{+} \mathrm{PCR}$, we observed that the rate of response was statistically lower in the $\mathrm{HPV}^{+}$group $(\mathrm{P}=0.02)$. Concerning patient outcomes in terms of recurrence and survival, we observed that the prognosis was poorer for $\mathrm{HPV}^{+}$patients. We showed for the first time that patients with $\mathrm{HPV}^{+} \mathrm{HNSCC}$ present with a worse prognosis after CCR. This observation highlights the need for prospective studies with large numbers of patients and a detailed history of tobacco
\end{abstract}

Correspondence to: Dr Sven Saussez, Laboratory of Anatomy, Faculty of Medicine and Pharmacy, University of Mons, Pentagone 2A Avenue du Champ de Mars 6, B-7000 Mons, Belgium

E-mail: sven.saussez@umons.ac.be

${ }^{*}$ Contributed equally

Key words: human papillomavirus, head and neck, cancer, chemoradiotherapy, prognosis and alcohol consumption before validating HPV as a marker of prognosis following CCR.

\section{Introduction}

Head and neck squamous cell carcinomas (HNSCCs) remain a significant cause of morbidity worldwide, with as many as 466,831 and 168,368 cases diagnosed in 2008 among men and women, respectively (1-3). HNSCC patients with early clinical stage disease (stages I and II) have similar survival rates, with a 5-year survival rate between 70 and $90 \%$, independent of the sublocation or the treatment (surgery vs. radiotherapy) (4). In contrast, HNSCC patients with advanced clinical stage disease (stages III and IV) display different survival rates depending on the histological type of the tumor and its sublocation $(4,5)$. In this group, the combination of chemotherapy and radiotherapy allows for a better local-regional control rate of up to $65 \%(6,7)$. However, the obvious benefit of chemotherapy is associated with higher (grade III and IV) toxicity and mortality (8). It is, therefore, crucial to predict which patients will not benefit from concomitant chemoradiotherapy (CCR).

During the last 30 years, we have observed a clear increase in the incidence of carcinomas arising from the oral cavity and the oropharynx in the United States and in Europe, whereas the incidence of laryngeal carcinoma has been stable or has decreased slightly (9). This observation led us to propose that human papillomavirus (HPV) infection is a new risk factor for HNSCC in younger, non-smoking and non-drinking patients. In this subpopulation of HNSCC patients, $\mathrm{HPV}^{+}$tumors occur more frequently in the oropharynx than in other sites and appear to have a more favorable prognosis than $\mathrm{HPV}^{-}$carcinomas $(10,11)$. The better prognosis of $\mathrm{HPV}^{+}$tumors was also reported for advanced oropharyngeal carcinomas treated by CCR (12-20). However, HPV-associated tumors have a different pathogenesis with less chromosomal aberrations than tumors caused by alcohol and tobacco abuse. In Belgium, 
the situation is more complex since our HNSCC patients present with a higher incidence of HPV positivity associated with alcohol and tobacco abuse. In this context, we recently described that oral cavity $\mathrm{HPV}^{+}$carcinomas are associated with a worse prognosis that of $\mathrm{HPV}^{-}$carcinomas (21). The aim of the present study was to assess the impact of HPV positivity on the response to CCR in a series of 72 HNSCC patients.

\section{Materials and methods}

Histopathological and clinical data. Formalin-fixed, paraffinembedded HNSCC specimens were obtained from 72 patients (57 males, 15 females) who underwent concomitant chemoradiotherapy at the Saint-Pieter Hospital (Brussels) and Epicura (Baudour). The clinical data collected from this series of 72 HNSCC patients are described in Table I. This prospective and retrospective study was approved by the Institutional Review Board (AK/09-09-47/3805AD).

DNA extraction. The formalin-fixed, paraffin-embedded tissue samples $(\mathrm{n}=72)$ were sectioned $(10 \times 5 \mu \mathrm{m})$, de-paraffinized and digested with proteinase $\mathrm{K}$ by overnight incubation at $56^{\circ} \mathrm{C}$. DNA was purified using the QIAamp DNA Mini Kit (Qiagen, Benelux, Belgium) according to the manufacturer's recommended protocol.

Detection of HPV by polymerase chain reaction (PCR) amplification. HPV detection was performed using PCR with $\mathrm{GP}^{+} / \mathrm{GP}^{+}$primers (synthesized by Eurogentec, Liege, Belgium). The $\mathrm{GP}^{+} / \mathrm{GP}^{+}$primers amplify a consensus region located within the L1 region of the HPV genome. The PCR amplification of the HPV-L1 DNA was performed in a $25-\mu 1$ reaction mixture containing $2 \mu \mathrm{l}$ of extracted DNA, $2.5 \mu \mathrm{l} 1 \mathrm{X}$ PCR buffer, $0.025 \mathrm{U}$ Taq DNA polymerase (Roche, Mannheim, Germany), $200 \mu \mathrm{M}$ DNTPs and $0.5 \mathrm{pmol}$ of each primer. The cycling conditions for the PCR were as follows: denaturation was performed at $94^{\circ} \mathrm{C}$ for $1 \mathrm{~min}$, annealing was performed at $55^{\circ} \mathrm{C}$ for $1 \mathrm{~min}$ and $30 \mathrm{sec}$, and extension was performed at $72^{\circ} \mathrm{C}$ for $2 \mathrm{~min}$, for a total of 45 amplification cycles. The first cycle was preceded by a 7-min denaturation step at $94^{\circ} \mathrm{C}$, and the last cycle was followed by an additional 10 -min extension step at $72^{\circ} \mathrm{C}$. Aliquots $(10 \mu \mathrm{l})$ of each PCR product were electrophoresed through a $1.8 \%$ agarose gel and stained with ethidium bromide to visualize the amplified HPV-L1 DNA fragments.

Real-time quantitative PCR amplification of the HPV typespecific DNA. All DNA extracts were tested for the presence of 18 different HPV genotypes using TaqMan-based real-time quantitative PCR that targeted type-specific sequences of the following viral genes: $6 \mathrm{E} 6,11 \mathrm{E} 6,16 \mathrm{E} 7,18 \mathrm{E} 7,31 \mathrm{E} 6,33$ E6, 35 E6, 39 E7, 45 E7, 51 E6, 52 E7, 53 E6, 56 E7, 58 E6, $59 \mathrm{E} 7,66 \mathrm{E} 6,67 \mathrm{~L} 1$ and $68 \mathrm{E} 7$ (22). For the various real-time quantitative PCR assays, the analytical sensitivity ranged from 1 to 100 copies and was calculated using standard curves generated with plasmids containing the entire genome of the different HPV types (23). Real-time quantitative PCR for the detection of $\beta$-globin was performed in each PCR assay to verify the quality of DNA in the samples and to measure the amount of input DNA $(23,24)$. The following HPV types tested

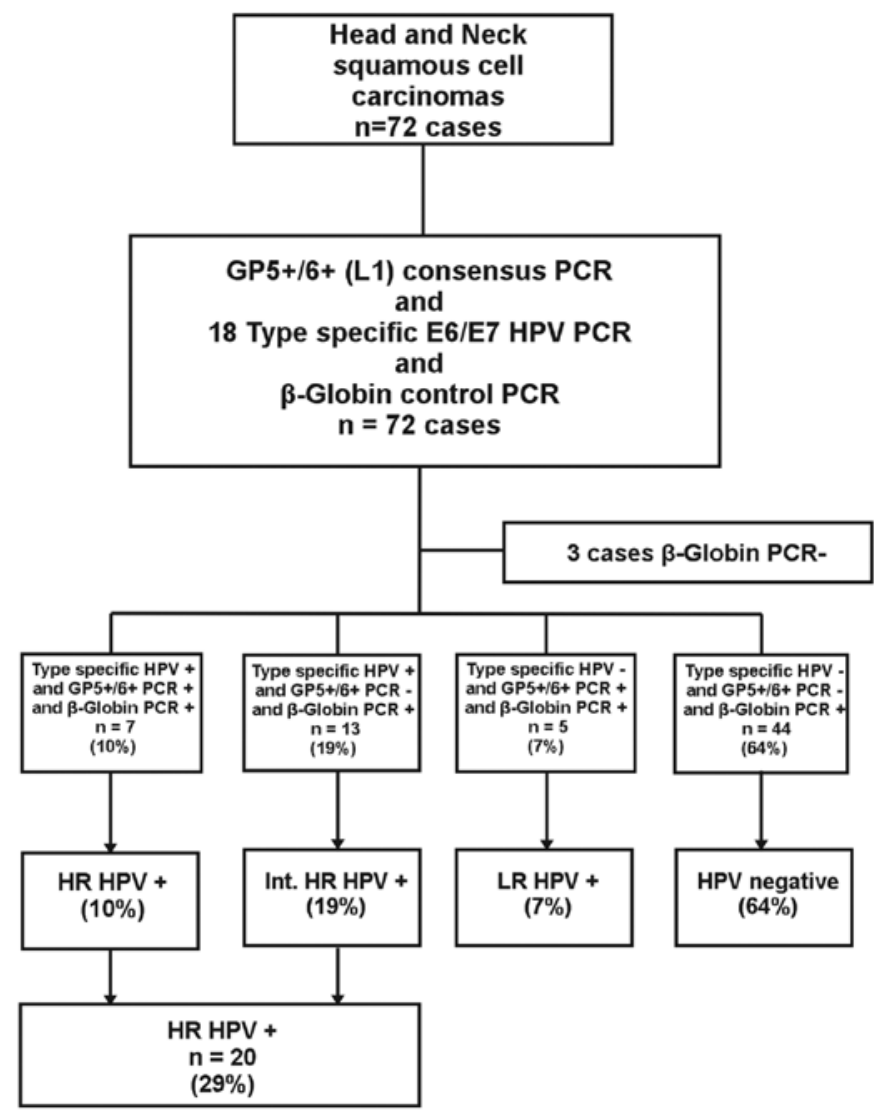

Figure 1. HPV PCR results from 72 HNSCC cases. $\beta$-globin could not be amplified in three samples; therefore, a total of 69 cases were analyzed using type-specific real-time $\mathrm{PCR}$ and $\mathrm{GP}^{+} / \mathrm{GP}^{+}$consensus PCR. Among these patients, $29 \%$ tested positive for infection with one or several types of HR HPV, 7\% tested positive for LR HPV and 64\% were HPV-negative. HR, high risk; LR, low risk.

were considered high-risk (HR): $16,18,31,33,35,39,45,51$, $52,53,56,58,59$ and 66 .

\section{Results}

HPV status in our clinical series of HNSCC patients treated by $C C R$. Of the 72 cases, three were excluded from further analysis since $\beta$-globin could not be amplified (Fig. 1). Ultimately, $69 \beta$-globin PCR-positive specimens were typed by quantitative real-time PCR using primers for 18 different HPV types. We identified 20 (29\%) patients whose tumors tested positive for the following HR HPV types: 16 (15 cases), 59 ( 2 cases), 53 ( 2 cases), 58 (1 case), 66 (1 case) and 67 (1 case). One patient was infected with multiple types of HR HPV (HPV 59 E7 and HPV 33, 52, 58, 67 L1). Among the 20 patients with $\mathrm{HR} \mathrm{HPV}^{+}$tumors, 7 tumors were both $\mathrm{GP}^{+} / \mathrm{GP}^{+}$positive (L1 detection) and type-specific HPV positive $\left(\mathrm{HR} \mathrm{HPV}^{+}\right.$ group). However, 13 tumors were $\mathrm{GP}^{+} / \mathrm{GP}^{+}$negative and type-specific HPV positive, corresponding to an integrated $\mathrm{HPV}^{+}$group (int. $\mathrm{HR} \mathrm{HPV}^{+}$). In the HR HPV-negative group $(\mathrm{n}=49), 5$ patients tested positive for HPV using the $\mathrm{GP}^{+} /$ $\mathrm{GP}^{+}$consensus primers and were considered to be infected with low-risk (LR) HPV types. Forty-four tumors (64\%) were negative for both $\mathrm{GP}^{+} / \mathrm{GP}^{+}$and type-specific HPV upon PCR analysis (Fig. 1). 
Table I. Clinical data of the HNSCC patients.

Variable Patients $(\mathrm{n}=72)$

\section{Gender}

Male 57

Female

Age (years)

Mean

Range

Localization

Oral cavity

Oropharynx

Hypopharynx

Larynx

19

29

12

12

Grade (differentiation)

Well

29

Moderate

Poor

In situ

Not recorded

TNM stage

T1N2

T1N3

T2N0

T2N1

T2N2

T3N0

T3N1

T3N2

T4N0

T4N1

T4N2

T4N3

TNM stage I-IV

$$
\text { I }
$$

II

III

IV

Risk factors

Tobacco

Smoker

Non-smoker

Former smoker

Alcohol

Drinker

Non-drinker

Former drinker

Treatment

Cisplatin $100 \mathrm{mg} / \mathrm{m}^{2}$ (Day 1-21-42)

Two doses

Three doses

Cisplatin $40 \mathrm{mg} / \mathrm{m}^{2}$ (weekly)

Carboplatin (weekly)

Cisplatin $100 \mathrm{mg} / \mathrm{m}^{2}$ (1 cycle) and carboplatin $40 \mathrm{mg} / \mathrm{m}^{2}$ (weekly)
Table I. Continued.

\begin{tabular}{|c|c|}
\hline Variable & Patients $(n=72)$ \\
\hline Erbitux & 18 \\
\hline $\begin{array}{l}\text { Erbitux ( } 2 \text { cycles) and cisplatin } \\
40 \mathrm{mg} / \mathrm{m}^{2} \text { (weekly) }\end{array}$ & 1 \\
\hline Carboplatin $+5 \mathrm{FU}$ & 1 \\
\hline $\begin{array}{l}\text { Cisplatin } 100 \mathrm{mg} / \mathrm{m}^{2}(2 \text { cycles }) \\
\text { and erbitux }(1 \text { cycle })\end{array}$ & 1 \\
\hline \multicolumn{2}{|l|}{ Radiotherapy (n=70) } \\
\hline $70 \mathrm{~Gy}$ & 66 \\
\hline$>70 \mathrm{~Gy}$ & 1 \\
\hline$<70 \mathrm{~Gy}$ & 3 \\
\hline \multicolumn{2}{|l|}{ Responders } \\
\hline Yes & 38 \\
\hline No & 34 \\
\hline \multicolumn{2}{|l|}{ Lymph node dissection } \\
\hline Yes & 10 \\
\hline Positive node & 3 \\
\hline Negative node & 7 \\
\hline No & 62 \\
\hline \multicolumn{2}{|l|}{ Recurrence } \\
\hline Local & 10 \\
\hline Nodal & 5 \\
\hline Distant metastases & 4 \\
\hline Local + distant metastases & 1 \\
\hline Nodal + distant metastases & 1 \\
\hline \multicolumn{2}{|l|}{ Follow-up ${ }^{a}$} \\
\hline Range (months) & $1-106$ \\
\hline Mean (months) & 30 \\
\hline
\end{tabular}

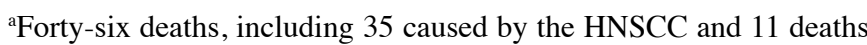
that were unrelated to HNSCC.

Correlation between HPV detection and clinical data. The $\mathrm{HPV}^{+}$group was composed of more men $(\mathrm{n}=20,77 \%)$ than women $(n=6,23 \%)$. The age ranged from 43 to 78 years, and most patients had stage IV disease (4 had stage III and 22 had stage IV). There was a clear predominance of smokers $(\mathrm{n}=19$, $73 \%)$ or former smokers $(n=6,23 \%)$ and drinkers $(n=23,88 \%)$ or former drinkers $(\mathrm{n}=1,4 \%)$ compared to patients who did not consume tobacco $(\mathrm{n}=1,4 \%)$ or alcohol $(\mathrm{n}=2,8 \%)$ (Table I). However, no statistical correlation was found between the HPV status and the following clinical data: gender, smoking status, alcohol status, sublocation, differentiation, $\mathrm{T}$ and $\mathrm{N}$ stage.

Correlation between HPV detection and of response rate to $C C R$. When analyzing the impact of HPV positivity on the rate of response and non-response to CCR, we tested the potential correlation using the two tests $\left(\mathrm{GP}^{+} / \mathrm{GP}^{+} \mathrm{PCR}\right.$ and $\left.\mathrm{qPCR}\right)$ separately and also in combination. We investigated whether one of these two tests or their combination could predict the response to CCR. Interestingly, using the $\mathrm{PCR} \mathrm{GP}^{+} / \mathrm{GP}^{+}$ as a tool for HPV detection, the rate of response to CCR 
A

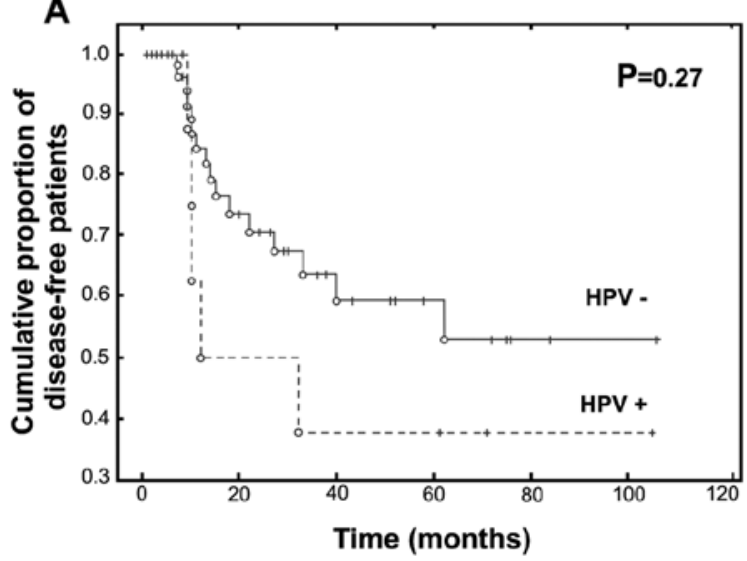

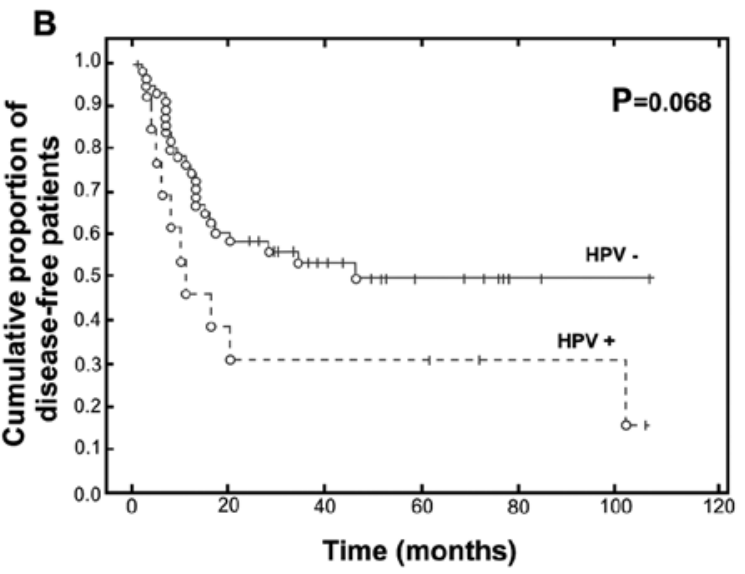

Figure 2. These graphs show, respectively, the recurrence rate (A) and the survival rate (B) of patients with $\mathrm{HPV}^{+}$and $\mathrm{HPV}^{-}$carcinomas. Both analyses reveal a less favorable prognosis for the $\mathrm{HPV}^{+}$subgroup, with a recurrence rate of $38 \mathrm{vs} .27 \%$ for $\mathrm{HPV}^{-}$patients $(\mathrm{P}=0.27)(\mathrm{A})$ and a survival rate at 5 years of 23 vs. 57\% for the $\mathrm{HPV}^{-}$population $(\mathrm{P}=0.068)(\mathrm{B})$. The percentages shown in the two curves do not represent the total number of patients since the follow-up of several patients was shorter than the first event of recurrence or death. Standard survival time analyses were performed using Kaplan-Meier curves, the Gehan-Wilcoxon text and the log-rank test.

Table II. Studies that found a positive correlation between HPV and response to chemoradiotherapy in HNSCCs.

\begin{tabular}{|c|c|c|c|c|c|c|}
\hline Authors (ref.) & $\begin{array}{l}\text { No. of } \\
\text { patients }\end{array}$ & $\begin{array}{c}\text { HPV } \\
\text { prevalence }(\%)\end{array}$ & Anatomical site & $\begin{array}{l}\text { Smokers } \\
\text { (n) }\end{array}$ & $\begin{array}{l}\text { Drinkers } \\
(\mathrm{n})\end{array}$ & Detection methods \\
\hline Kumar et al (12) & 42 & 64 & Oropharynx & 34 & Not listed & qPCR \\
\hline Chung et al (17) & 46 & 50 & Oropharynx & Not listed & Not listed & $\begin{array}{l}\text { PCR in situ } \\
\text { hybridization }\end{array}$ \\
\hline Nichols et al (18) & 44 & 61 & Oropharynx & Not listed & Not listed & In situ hybridization \\
\hline Fallai et al (20) & 22 & 23 & Oropharynx & Not listed & Not listed & qPCR \\
\hline de Jong et al (19) & 75 & 49 & $\begin{array}{l}\text { Pharynx } \\
\text { Oral cavity }\end{array}$ & Not listed & Not listed & Genetic signature \\
\hline Rischin et al (13) & 172 & 65 & Oropharynx & 111 & Not listed & $\begin{array}{l}\text { PCR in situ } \\
\text { hybridization }\end{array}$ \\
\hline Hong et al (15) & 35 & 24 & $\begin{array}{l}\text { Head and neck squamous } \\
\text { cell carcinomas }\end{array}$ & Not listed & Not listed & qPCR \\
\hline Lill et al (14) & 29 & 38 & $\begin{array}{l}\text { Head and neck squamous } \\
\text { cell carcinomas }\end{array}$ & Not listed & Not listed & $\begin{array}{l}\text { PCR in situ } \\
\text { hybridization }\end{array}$ \\
\hline
\end{tabular}

was statistically lower, with $23 \%$ of responders in the $\mathrm{HPV}^{+}$ group against $59 \%$ in the $\mathrm{HPV}^{-}$group $(\mathrm{P}=0.02$, Fisher's exact test). There was no statistical correlation between the type of chemotherapy administered and the number of responders according to HPV status determined through consensus PCR or qPCR. Using the qPCR for HPV detection, no statistical correlation was observed, and the rate of response was lower in the $\mathrm{HPV}^{+}$group (50\%) than in the $\mathrm{HPV}^{-}$group (57\%).

Correlation between HPV infection and prognosis in HNSCC patients. Based on the $\mathrm{GP}^{+} / \mathrm{GP}^{+} \mathrm{PCR}$ detection, we observed that the $\mathrm{HPV}^{+}$group exhibited a worse prognosis in terms of survival. In fact, the recurrence rate was higher in patients with $\mathrm{HPV}^{+}$carcinomas, at $38 \%$, while it reached only $27 \%$ among patients with $\mathrm{HPV}^{-}$carcinomas (log-rank test, $\mathrm{P}=0.27$ ) (Fig. 2A). However, the treatment did not influ- ence the recurrence rate; there was no significant difference between patients who received platin or erbitux. Therefore, the disease-free survival rate at 5 years was $57 \%$ for patients with $\mathrm{HPV}^{-}$carcinoma vs. $23 \%$ for patients with $\mathrm{HPV}^{+}$carcinoma (Gehan-Wilcoxon test, $\mathrm{P}=0.068$ ) (Fig. 2B).

The percentages shown in the two curves do not represent the total number of patients. The follow-up of several patients was shorter than the first event of recurrence or death.

\section{Discussion}

In the early 2000s, with the advent of CCR, we observed a clear increase in the 5-year disease-free survival of HNSCC stage IV patients, from 45 to $66 \%$ (25). However, CCR was also associated with significant morbidity and mortality (notably, a higher incidence of dysphonia and dysphagia) (26). Therefore, clinicians are 
searching for new reliable prognostic markers of CCR response and are considering the growing interest in HPV infection in the biology of HNSCC. We decided to investigate whether a correlation exists between HPV positivity and the response to CCR in a series of 72 HNSCC patients with a history of tobacco and alcohol use (in more than $90 \%$ of our population).

In our study, the prevalence of HPV positivity reached $36 \%$, with $29 \%$ of samples containing HR HPV DNA and $7 \%$ of samples containing LR HPV DNA. Moreover, we observed that the rate of response was statistically lower in the $\mathrm{HPV}^{+}$ group. Several studies have reported that HPV DNA detection was closely correlated to a more favorable prognosis in HNSCC patients treated with CCR (Table II) (12-20).

We recently revealed, in a large clinical series of 162 oral cavity carcinoma patients, that $\mathrm{HPV}^{+}$tumors were significantly associated with a poorer prognosis (27). The association between HPV positivity and poor prognosis was also previously reported in two Swedish studies in which oral HPV infection was associated with a dramatically increased risk of oral squamous cell carcinoma (OSCC) development $(28,29)$. Clayman et al also showed that $\mathrm{HPV}^{+}$carcinomas were significantly correlated with a decreased survival rate (30). In fact, our results could be explained by the fact that our series was mainly composed of smokers and/or drinkers (Table I), which is contrary to the majority of studies describing a favorable prognosis for patients with $\mathrm{HPV}^{+}$tumors (Table II). It should also be emphasized that $\mathrm{HPV}^{+}$tumors related to tobacco and alcohol consumption constitute a distinct biological and clinical entity from $\mathrm{HPV}^{+}$tumors without classical risk factors, which are associated with a better outcome. In this regard, trends in smoking behavior in Europe present some significant differences (31). A greater decline in smoking habits was observed among Norwegian, Finnish and Dutch populations, highlighting that individuals in Northern European countries are less exposed to classical risk factors than those residing in Southern European countries (31). Therefore, all studies investigating the HPV status in HNSCC need to be interpreted with caution since many are small clinical series without information on the alcohol consumption and smoking status of their patients. Moreover, our clinical series was composed of patients with an extremely long-term follow-up (ranging from 0 to 106 months), which is a crucial point for assessing the prognostic implications of HPV infection.

A persistent HPV infection that can lead to the development of epithelial cancer requires immune tolerance. Thus, HPV has also developed several mechanisms to avoid detection by the host immune defense system, such as downregulation of INF- $\alpha$ and toll-like receptor 9 , production of TGF- $\beta$ and maintenance of low viremia (viral protein synthesis is confined to keratinocytes without an increase in cell death) (32-34). In the absence of cell lysis, there is little or no release of the proinflammatory cytokines that are crucial for the activation and migration of dendritic cells $(32,35)$. There are limited data describing the interaction between the host immune system during HPV infection in the context of HNSCC, which means that the role of innate and adaptive immunity in this context is largely unknown. As mentioned previously, in several studies, $\mathrm{HPV}^{+} \mathrm{HNSCC}$ was associated with an unfavorable outcome. From these results, some authors supported the hypothesis that immunosuppression favors HPV infection and that a failing immune response may be negative in terms of prognosis for $\mathrm{HPV}^{+} \mathrm{HNSCC}$. In fact, Tung et al reported the presence of HPV-16 or HPV-18 and the Epstein Barr virus in $80 \%$ of nasopharyngeal carcinoma samples (36). Another study showed that herpes simplex virus-2 infection was associated with an increased risk of HPV infection (37). In 2004, Kreimer et al demonstrated that tonsillar HPV infection was strongly associated with HIV co-infection and immunosuppression (38). More recently, we studied different markers of the immune system in a large series of $110 \mathrm{HNSCC}$ cases $\left(36 \mathrm{HPV}^{+}\right.$cases vs. $74 \mathrm{HPV}^{-}$cases) to study the involvement of HPV infection in the alterations of the immune system in a population of smokers and drinkers. We observed a significant decrease in the number of natural killer cells and dendritic cells in $\mathrm{HPV}^{+}$ samples compared to $\mathrm{HPV}^{-}$samples (unpublished data).

In conclusion, we showed for the first time, in a clinical series of $72 \mathrm{HNSCC}$ patients, that the rate of response to CCR was statistically lower in the $\mathrm{HPV}^{+}$group. Notably, the association between HPV positivity and an unfavorable prognosis was discovered in a population of smokers and drinkers with HNSCC. Our study also highlights the need for prospective, controlled studies with larger numbers of patients, a detailed history of tobacco and alcohol use among patients, and homogeneous treatments and anatomical sites in order to confirm the impact of HPV infection in HNSCCs treated with CCR.

\section{Acknowledgements}

Anaëlle Duray and Géraldine Descamps are PhD students supported by a grant from the FNRS (Bourse Televie). Christine Decaestecker is a Senior Researcher of the Belgian National Fund for Scientific Research (FNRS, Brussels, Belgium).

\section{References}

1. World Health Organization: International Agency for Research on Cancer. Globocan, 2008. Available from: http://globocan. iarc.fr/.

2. Grandis JR, Pietenpol JA, Greenberger JS, Pelroy RA and Mohla S: Head and neck cancer: meeting summary and research opportunities. Cancer Res 64: 8126-8129, 2004.

3. Shah JP and Patel SG: Head and Neck Surgery and Oncology. 3rd edition. Mosby, New York, pp232-236, 352, 2003.

4. Forastiere AA and Trotti A: Radiotherapy and concurrent chemotherapy: a strategy that improves locoregional control and survival in oropharyngeal cancer. J Natl Cancer Inst 91: 2065-2066, 1999.

5. Denis F, Garaud P, Bardet E, et al: Final results of the 94-01 French Head and Neck Oncology and Radiotherapy Group randomized trial comparing radiotherapy alone with concomitant radiochemotherapy in advanced-stage oropharynx carcinoma. J Clin Oncol 22: 69-76, 2004.

6. Stenson KM, Kunnavakkam R, Cohen EE, et al: Chemoradiation for patients with advanced oral cavity cancer. Laryngoscope 120: 93-99, 2010.

7. Milano MT, Vokes EE, Kao J, et al: Intensity-modulated radiation therapy in advanced head and neck patients treated with intensive chemoradiotherapy: preliminary experience and future directions. Int J Oncol 28: 1141-1151, 2006.

8. Hu M, Ampil F, Clark C, Sonavane K, Caldito G and Nathan CA: Comorbid predictors of poor response to chemoradiotherapy for laryngeal squamous cell carcinoma. Laryngoscope 122: 565-571, 2012 .

9. Sturgis EM and Cinciripini PM: Trends in head and neck cancer incidence in relation to smoking prevalence: an emerging epidemic of human papillomavirus-associated cancers? Cancer 110: 1429-1435, 2007. 
10. Dahlstrand H, Nasman A, Romanitan M, Lindquist D, Ramqvist T and Dalianis T: Human papillomavirus accounts both for increased incidence and better prognosis in tonsillar cancer. Anticancer Res 28: $1133-1138,2008$

11. Reimers N, Kasper HU, Weissenborn SJ, et al: Combined analysis of HPV-DNA, p16 and EGFR expression to predict prognosis in oropharyngeal cancer. Int J Cancer 120: 1731-1738, 2007.

12. Kumar B, Cordell KG, Lee JS, et al: Response to therapy and outcomes in oropharyngeal cancer are associated with biomarkers including human papillomavirus, epidermal growth factor receptor, gender, and smoking. Int J Radiat Oncol Biol Phys 69: 109-111, 2007.

13. Rischin D, Young RJ, Fisher R, et al: Prognostic significance of p16INK4A and human papillomavirus in patients with oropharyngeal cancer treated on TROG 02.02 phase III trial. J Clin Oncol 28: 4142-4148, 2010.

14. Lill C, Kornek G, Bachtiary B, et al: Survival of patients with HPV-positive oropharyngeal cancer after radiochemotherapy is significantly enhanced. Wien Klin Wochenschr 123: 215-221, 2011 .

15. Hong AM, Dobbins TA, Lee CS, et al: Human papillomavirus predicts outcome in oropharyngeal cancer in patients treated primarily with surgery or radiation therapy. Br J Cancer 103 1510-1517, 2010.

16. Sedaghat AR, Zhang Z, Begum S, et al: Prognostic significance of human papillomavirus in oropharyngeal squamous cell carcinomas. Laryngoscope 119: 1542-1549, 2009.

17. Chung YL, Lee MY, Horng CF, et al: Use of combined molecular biomarkers for prediction of clinical outcomes in locally advanced tonsillar cancers treated with chemoradiotherapy alone. Head Neck 31: 9-20, 2009.

18. Nichols AC, Faquin WC, Westra WH, et al: HPV-16 infection predicts treatment outcome in oropharyngeal squamous cell carcinoma. Otolaryngol Head Neck Surg 140: 228-234, 2009.

19. de Jong MC, Pramana J, Knegjens JL, et al: HPV and high-risk gene expression profiles predict response to chemoradiotherapy in head and neck cancer, independent of clinical factors. Radiother Oncol 95: 365-370, 2010.

20. Fallai C, Perrone F, Licitra L, et al: Oropharyngeal squamous cell carcinoma treated with radiotherapy or radiochemotherapy: prognostic role of TP53 and HPV status. Int J Radiat Oncol Biol Phys 75: 1053-1059, 2009.

21. Pim D, Collins M and Banks L: Human papillomavirus type 16 E5 gene stimulates the transforming activity of the epidermal growth factor receptor. Oncogene 7: 27-32, 1992.

22. Depuydt CE, Benoy IH, Bailleul EJ, Vandepitte J, Vereecken AJ and Bogers JJ: Improved endocervical sampling and HPV viral load detection by Cervex-Brush Combi. Cytopathology 17 374-381, 2006

23. Depuydt CE, Boulet GA, Horvath CA, Benoy IH, Vereecken AJ and Bogers JJ: Comparison of MY09/11 consensus PCR and type-specific PCRs in the detection of oncogenic HPV types. J Cell Mol Med 11: 881-891, 2007.
24. Arbyn M,Benoy I, Simoens C, Bogers J, Beutels P and Depuydt C: Prevaccination distribution of human papillomavirus types in women attending at cervical cancer screening in Belgium. Cancer Epidemiol Biomarkers Prev 18: 321-330, 2009.

25. Filleul O, Preillon J, Crompot E, Lechien J and Saussez S: Incidence of head and neck cancers in Belgium: comparison with worldwide and French data. Bulletin du Cancer 98: 1173-1183, 2011.

26. Saussez S: Cancer of the upper aero-digestive tract: elevated incidence in Belgium, new risk factors and therapeutic perspectives. Bull Mem Acad R Med Belg 165: 453-461, 2010.

27. Duray A, Descamps G, Decaestecker C, et al: Human papillomavirus DNA strongly correlates with a poorer prognosis in oral cavity carcinoma. Laryngoscope 122: 1558-1565, 2012.

28. Rosenquist K, Wennerberg J, Annertz K, et al: Recurrence in patients with oral and oropharyngeal squamous cell carcinoma: human papillomavirus and other risk factors. Acta Otolaryngol 127: 980-987, 2007.

29. Hansson BG, Rosenquist K, Antonsson A, et al: Strong association between infection with human papillomavirus and oral and oropharyngeal squamous cell carcinoma: a population-based case-control study in southern Sweden. Acta Otolaryngol 125: $1337-1344,2005$

30. Clayman GL, Stewart MG, Weber RS, el-Naggar AK and Grimm EA: Human papillomavirus in laryngeal and hypopharyngeal carcinomas. Relationship to survival. Arch Otolaryngol 120: 743-748, 1994.

31. Giskes K, Kunst AE, Benach J, et al: Trends in smoking behavior between 1985 and 2000 in nine European countries by education. J Epidemiol Community Health 59: 395-401, 2005.

32. Stanley MA: Immune responses to human papillomaviruses. Indian J Med Res 130: 266-276, 2009.

33. Hasan UA, Bates E, Takeshita F, et al: TLR9 expression and function is abolished by the cervical cancer-associated human papillomavirus type 16. J Immunol 178: 3186-3197, 2007.

34. Lepique AP, Daghastanli KR, Cuccovia IM and Villa LL: HPV16 tumor associated macrophages suppress antitumor T cell responses. Clin Cancer Res 15: 4391-4400, 2009.

35. Stanley MA: Immune responses to human papillomavirus. Vaccine 24: 16-22, 2006

36. Tung YC, Lin KH, Chu PY, Hsu CC and Kuo WR: Detection of human papillomavirus and Epstein Barr virus DNA in nasopharyngeal carcinoma by polymerase chain reaction. Kaohsiung J Med Sci 15: 256-262, 1999.

37. Moscicki AB, Hills N, Shiboski S, et al: Risks for incident human papillomavirus infection and low-grade squamous intraepithelial lesion development in young females. JAMA 285: 2995-3002, 2001.

38. Kreimer AR, Alberg AJ, Daniel R, et al: Oral human papillomavirus infection in adults is associated with sexual behavior and HIV serostatus. J Infect Dis 189: 686-698, 2004. 